\title{
FoxM1 promotes epithelial-mesenchymal transition of hepatocellular carcinoma by targeting Snai1
}

\author{
CHUN-PENG YU ${ }^{1 *}$, SHUI YU ${ }^{2 *}$, LEI SHI ${ }^{1}$, SONG WANG $^{2}$, ZI-XIANG LI ${ }^{2}$, \\ YAN-HUA WANG ${ }^{2}$, CHENG-JIAN SUN ${ }^{2}$ and JUN LIANG ${ }^{1}$ \\ ${ }^{1}$ Department of Oncology; ${ }^{2}$ Department of Interventional Medical Center, The Affiliated Hospital \\ of Qingdao University Medical College, Qingdao, Shandong 266003, P.R. China
}

Received July 30, 2016; Accepted May 15, 2017

DOI: $10.3892 / \mathrm{mmr} .2017 .7223$

\begin{abstract}
Forkhead box protein M1 (FoxM1) is aberrantly expressed in several types of human malignancy, and serves an important role in tumor metastasis. Epithelial-mesenchymal transition (EMT) of cancer cells has been associated cancer metastasis; however, the implication of FoxM1 in EMT and its putative roles in the regulation of cancer metastasis remain to be elucidated. In the present study, the expression of FoxM1, Snail and E-cadherin in hepatocellular carcinoma (HCC) cell lines with various metastatic potentials, and in normal liver cells, was investigated using western blot analysis and reverse transcription-quantitative polymerase chain reaction. The effects of FoxM1 on the invasive and migratory capabilities of HCC cells were evaluated using wound healing and Transwell migration assays. The present results demonstrated that FoxM1 expression was significantly upregulated in HCC cells compared with in normal hepatocytes $(\mathrm{P}<0.05)$. In addition, FoxM1 expression was significantly increased in MHCC-LM3 cells, characterized by higher metastatic potential, compared with in SMMC-7721 cells, which have a lower metastatic potential. Furthermore, overexpression of FoxM1 was demonstrated to be negatively correlated with E-cadherin $(\mathrm{P}<0.05)$ and positively associated with Snail $(\mathrm{P}<0.05)$ expression. These observations suggested that FoxM1 may enhance the invasion and migration of cancer cells, and thus promotes their EMT, in a mechanism that may involve the regulation of Snai1.
\end{abstract}

Correspondence to: Dr Jun Liang, Department of Oncology, The Affiliated Hospital of Qingdao University Medical College, 16 Jiangsu Road, Qingdao, Shandong 266003, P.R. China

E-mail: ljqyfy@163.com

Dr Cheng-Jian Sun, Department of Interventional Medical Center, The Affiliated Hospital of Qingdao University Medical College, 16 Jiangsu Road, Qingdao, Shandong 266003, P.R. China

E-mail: chengjiansun2009@163.com

*Contributed equally

Key words: forkhead transcription factors, liver neoplasm, cadherins, epithelial-mesenchymal transition, Snai1, neoplasm metastasis
Therefore, it may be hypothesized that FoxM1 has potential as a novel diagnostic marker and therapeutic target for the treatment of patients with HCC.

\section{Introduction}

Hepatocellular carcinoma (HCC) is one of the most common types of human cancer, ranking 3rd among all causes of cancer-associated mortality in China, following gastric and esophageal cancer, whereas the mortality rate of patients with HCC was reported to be $\sim 50 \%$ in 2011 (1). The most common causes of mortality in patients with HCC have been identified as cancer recurrence, metastasis and deterioration of original tumors (2). At present, tumor resection and liver transplantation are the main therapeutic strategies for the treatment of patients with HCC. However, diagnosis at an advanced stage is very common, when the high rate of metastasis and the lack of specific tumor marks do not permit tumor resection; therefore, only a small number of patients with HCC are suitable for surgical treatment (3). In addition, the high risk of metastasis and recurrence, even among surgically-treated patients, limits the survival rate of patients with HCC (4). Therefore, it is imperative to elucidate the molecular mechanisms underlying the recurrence and metastasis of $\mathrm{HCC}$, in order to develop novel therapeutic strategies for the treatment of patients with HCC.

Greenburg and Hay (5) first proposed the term epithelial to mesenchymal transition (EMT) in 1982. EMT is defined as the loss of epithelial differentiation and a shift towards a mesenchymal phenotype. This process is characterized by a downregulation in the expression of epithelial markers, including E-cadherin, a loss of intercellular junctions, reduced intercellular adhesion, cytoskeletal changes, increased cell motility and overexpression of mesenchymal genes, such as vimentin and $\mathrm{N}$-cadherin (6). Among the aforementioned processes, E-cadherin downregulation has been used as a molecular marker for the detection of EMT. A previous study reported that loss of E-cadherin was associated with the intrahepatic metastasis of HCC cells (7). In addition, EMT has been identified as a key mechanism during cancer metastasis, and its roles have been demonstrated in various types of human cancer, including gastric, mammary and prostate cancer (8-11). Therefore, the elucidation of the molecular mechanisms 
involved in EMT is imperative for the development of effective strategies for the inhibition of HCC metastasis.

Forkhead box protein M1 (FoxM1) belongs to the Fox family of transcription factors, which are characterized by the presence of an evolutionarily conserved winged-helical DNA-binding domain (12). Fox proteins are involved in the regulation of numerous physiological processes, including cell differentiation, proliferation and apoptosis, and the maintenance of stem cell pluripotency $(12,13)$. FoxM1 is expressed in almost all embryonic tissues, particularly in proliferating epithelial mesenchymal cells, whereas it is not expressed in non-proliferating cells (14). In addition, FoxM1 is expressed in adult lung and intestinal tissues, with high expression levels in the thymus and testis $(13,15,16)$. Several studies have suggested the function of FoxM1 as an oncogene in various types of malignancies, including liver (17), gastric (18) and colon cancer (19). FoxM1 has also been demonstrated to serve essential roles in tumor angiogenesis, invasion and metastasis $(20,21)$. However, the roles of FoxM1 in the migration and invasion of HCC cells remain to be elucidated, and the molecular mechanisms regulating its functions are unclear.

In the present study, the involvement of FoxM1 in EMT was investigated in human HCC cell lines. The expression of FoxM1 and E-cadherin was detected and their correlation was assessed. FoxM1 was identified to be negatively correlated with E-cadherin in HCC cells with higher metastatic potential, thus suggesting that FoxM1 may function as an oncogene in liver cancer.

\section{Materials and methods}

Reagents. Dulbecco's modified Eagle's medium (DMEM), fetal bovine serum (FBS), penicillin and streptomycin were purchased from Invitrogen; Thermo Fisher Scientific, Inc. (Waltham, MA, USA). Primary antibodies against FoxM1 (cat. no. ab175798), snail family transcriptional repressor 1 (Snai1; cat. no. ab53519) and E-cadherin (cat. no. ab76055) were purchased from Abcam (Cambridge, UK). Anti-rabbit and anti-mouse horseradish peroxidase (HRP)-conjugated secondary antibodies (cat. nos. 5436, 3895 and 3195) were obtained from Cell Signaling Technology, Inc. (Danvers, MA, USA). GAPDH polyclonal antibody (cat. no. SC-32233) was procured from Santa Cruz Biotechnology, Inc. (Dallas, TX, USA). Small interfering (si)RNA targeting FoxM1 and the FoxM1 expression vector pcDNA3.1-FoxM1 were purchased from Abcam. TRIzol ${ }^{\circledR}$ reagent was purchased from Invitrogen; Thermo Fisher Scientific, Inc. PrimeScript ${ }^{\mathrm{TM}}$ RT reagent kit was purchased from Takara Bio, Inc. (Otsu, Japan). The transfection reagent was Lipofectamine 3000 (Invitrogen; Thermo Fisher Scientific, Inc.). Matrigel matrix was purchased from BD Biosciences (Franklin Lakes, NJ, USA).

Cell lines and culture conditions. Human SK-Hep1, MHCC-LM3 and SMMC-7721 HCC cell lines and the human HL-7702 normal liver cell line were purchased from the Shanghai Institute of Biochemistry and Cell Biology, Shanghai Institutes for Biological Sciences, Chinese Academy of Sciences (Shanghai, China). All cell lines were cultured in DMEM supplemented with $10 \% \mathrm{FBS}, 1 \%$ penicillin and $1 \%$ streptomycin, and were maintained at $37^{\circ} \mathrm{C}$ in a $5 \% \mathrm{CO}_{2}$ atmosphere.
Cell transfection. siRNA-FoxM1 (sequence, 5'-CACUAUCAA CAAUAGCCUATT-3') was used to silence the expression of FoxM1 in MHCC-LM3 cells, whereas pcDNA3.1-FoxM1 was used to overexpress FoxM1 in SMMC-7721 cells and SK-Hep1 cells. Non-targeting siRNA (sequence, 5'-GGUGUC GUGGUGGAAGUUUTT-3') and empty pcDNA3.1 vector were used as negative controls (NC). Cells were seeded into 6 -well plates and grown to $60-70 \%$ confluence at $37^{\circ} \mathrm{C}$ in an atmosphere containing $5 \% \mathrm{CO}_{2}$. Subsequently, they were transfected at $37^{\circ} \mathrm{C}$ with $100 \mathrm{nM}$ siRNA-FoxM1 and $4 \mu \mathrm{g}$ pcDNA3.1-FoxM1, or $40 \mathrm{pmol} / 1$ non-targeting siRNA and $4 \mu \mathrm{g}$ empty pcDNA3.1 vector, using Lipofectamine 3000, according to the manufacturer's protocol. Following $48 \mathrm{~h}$ of transfection, cells were harvested for subsequent experiments. The success of the transfection was determined using the reverse transcription-quantitative polymerase chain reaction (RT-qPCR), according to the protocol detailed below.

Western blot analysis. MHCC-LM3, SMMC-7721 and SK-Hep1 cells $\left(2 \times 10^{6}\right)$ were collected by centrifugation at $3,000 \mathrm{x}$ g for $5 \mathrm{~min}$ at $4^{\circ} \mathrm{C}$, and lysed in radioimmunoprecipitation assay lysis buffer (20 mM Tris- $\mathrm{HCl}$ pH 7.4, $100 \mathrm{mM}$ $\mathrm{NaCl}, 10 \% \mathrm{NP}-40,10 \%$ sodium deoxycholate and $100 \mathrm{mM}$ EDTA) at $0^{\circ} \mathrm{C}$ for $15 \mathrm{~min}$. Samples were subsequently centrifuged at $13,000 \mathrm{x} \mathrm{g}$ for $20 \mathrm{~min}$ at $4^{\circ} \mathrm{C}$. Protein concentration in the lysates was determined using a bicinchoninic acid protein assay (Pierce; Thermo Fisher Scientific, Inc.). Equal amounts of extracted protein samples $(20 \mu \mathrm{g})$ were separated by SDS-PAGE on a $1 \%$ gel and transferred onto polyvinylidene difluoride membranes. The membranes were blocked with $5 \%$ nonfat milk for $1.5 \mathrm{~h}$ at $37^{\circ} \mathrm{C}$, and then incubated with the following primary antibodies overnight at $4^{\circ} \mathrm{C}$ : Mouse polyclonal anti-FoxM1 (1:1,000), rabbit polyclonal anti-Snail $(1: 1,000)$, rabbit polyclonal anti-E-cadherin $(1: 1,000)$. Following washing with TBS containing $0.1 \%$ Tween-20, the membranes were incubated with HRP-conjugated anti-mouse $(1: 10,000)$ or anti-rabbit $(1: 10,000)$ secondary antibodies for $1 \mathrm{~h}$ at room temperature. Protein expression was normalized to GAPDH $(1: 1,000)$. Blots were visualized using enhanced chemiluminescence (Pierce; Thermo Fisher Scientific, Inc.) and semi-quantified by densitometric analysis using Image-Pro Plus software version 6.0 (Media Cybernetics, Inc., Rockville, MD, USA).

$R T-q P C R$ analysis. Total RNA was isolated using TRIzol ${ }^{\circledR}$ reagent, according to the manufacturer's protocol, from HL-7702, MHCC-LM3, SK-Hep1 and SMMC-7721 cells $\left(2 \times 10^{6}\right)$. Total RNA was reverse transcribed into cDNA $(2 \mu \mathrm{l})$ using the PrimeScript ${ }^{\mathrm{TM}}$ RT Reagent kit, according to the manufacturer's protocol. qPCR was performed using SYBR Green as a fluorophore, according to the manufacturer's protocol. The thermocycling conditions were as follows: Initial activation at $95^{\circ} \mathrm{C}$ for $10 \mathrm{~min}$, followed by 40 cycles at $95^{\circ} \mathrm{C}$ for $1 \mathrm{~min}$ (denaturation), at $55^{\circ} \mathrm{C}$ for $1 \mathrm{~min}$ (annealing), and at $60^{\circ} \mathrm{C}$ for $1 \mathrm{~min}$ (extension), followed by $60^{\circ} \mathrm{C}$ for $7 \mathrm{~min}$ for final extension and melting curve analysis. GAPDH served as an internal control to normalize gene expression. Relative gene expression was quantified using the comparative $\mathrm{Cq}$ method (22). The primers used in the present study were as follows: FoxM1, forward 5'-GCG ACA GGT TAA GGT TGA 

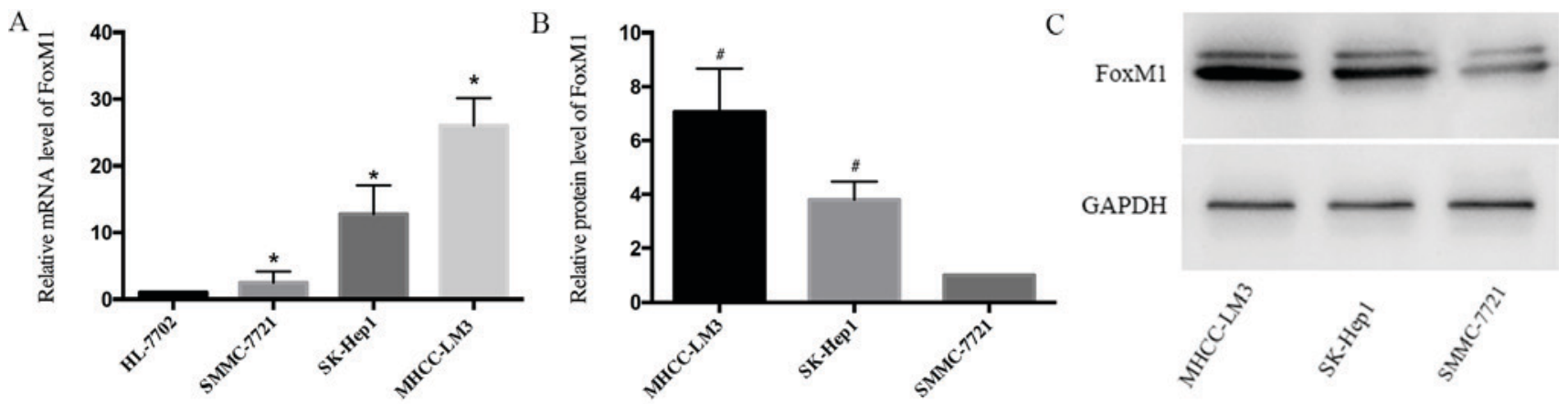

Figure 1. FoxM1 expression is upregulated in HCC cells. (A) Reverse transcription-quantitative polymerase chain reaction was used to assess the mRNA expression levels of FoxM1 in the human HL-7702 normal hepatocyte line and in the SMMC-7721, SK-Hep1 and MHCC-LM3 HCC cell lines (SMMC-7721 vs. HL-7702, P=0.048; SK-Hep1 vs. HL-7702, $\mathrm{P}=0.036$; MHCC-LM3 vs. HL-7702, $\mathrm{P}=0.013$ ). (B and C) Western blot analysis was used to assess the protein expression levels of FoxM1 in SMMC-7721, SK-Hep1 and MHCC-LM3 HCC cell lines (MHCC-LM3 vs. SMMC-7721, P=0.033; SK-Hep1 vs. SMMC-7721, $\mathrm{P}=0.029$ ). Data are expressed as the mean \pm standard deviation of 3 independent experiments. ${ }^{*} \mathrm{P}<0.05$ vs. HL-7702; ${ }^{\mathrm{P}}<0.05$ vs. SMMC-7721. Fox M1, forkhead box protein M1; HCC, hepatocellular carcinoma.

G-3' and reverse 5'-AGG TTG TGG CGG ATG GAG T-3'; Snail, forward 5'-TCT AGG CCC TGG CTG CTA CAA-3' and reverse 5'-ACA TCT GAG TGG GTC TGG AGG TG-3'; E-cadherin, forward 5'-TAA CCG ATC AGA ATG AC-3' and reverse 5'-TTT GTC AGG GAG CTC AGG AT-3'; and GAPDH, forward 5'-GCA CCG TCA AGG CTG AGA AC-3' and reverse 5'-ATG GTG GTG AAG ACG CCA GT-3'.

Wound-healing assay. An in vitro wound-healing assay was performed to assess the migratory capabilities of HCC cells. MHCC-LM3 cells ( $1 \mathrm{x}^{5}$ cells/well) transfected with siRNA-FoxM1 and SMMC-7721 cells $\left(1 \times 10^{5}\right.$ cells/well) transfected with pcDNA3.1-FoxM1 were plated in 12-well plates and cultured in DMEM supplemented with $10 \%$ FBS, $1 \%$ penicillin and $1 \%$ streptomycin, at $37^{\circ} \mathrm{C}$ with $5 \% \mathrm{CO}_{2}$ until $90-95 \%$ confluent. A scratch wound was generated with a $200 \mu \mathrm{l}$ pipette tip and cells were washed with PBS to remove debris. Subsequently, cells were cultured in DMEM containing 10\% FBS at $37^{\circ} \mathrm{C}$. The scratch wounds were observed at $0,12,24$ and $48 \mathrm{~h}$ under an optical microscope and photomicrographs were captured to analyze wound width using ImageJ $1.48 \mathrm{u}$ software (National Institutes of Health, Bethesda, MD, USA). Wound healing rate was calculated according to the following formula: Wound healing rate $=[$ (initial scratch width-scratch width at the specified time)/(initial scratch width)]x100\%.

Invasion and migration assays. In vitro Transwell assays were performed to assess the invasive and migratory capabilities of cancer cells. Cellular migration was assessed using Transwell inserts (Corning Incorporated, Corning, NY, USA) with $8.0 \mu \mathrm{m}$ pore size. A cell invasion assay was performed using Transwell inserts coated with Matrigel (75 $\mu 1 /$ well). Following $48 \mathrm{~h}$ of transfection, MHCC-LM3 cells transfected with siRNA-FoxM1 and SMMC-7721 cells transfected with pcDNA3.1-FoxM1 were seeded in the upper chambers of the inserts at a density of $1 \times 10^{5}$ cells/well in serum-free DMEM. DMEM containing $10 \%$ FBS was added to the lower chambers as a chemoattractant. Following culture for $24 \mathrm{~h}$ at $37^{\circ} \mathrm{C}$ in a $5 \% \mathrm{CO}_{2}$ atmosphere, cells on the surface of the upper chamber were removed by cotton swabs. The cells that had invaded the lower chamber were fixed with $10 \%$ methanol at $37^{\circ} \mathrm{C}$ for $15 \mathrm{~min}$, stained for $10 \mathrm{~min}$ at $37^{\circ} \mathrm{C}$ with $0.1 \%$ crystal violet and observed under an inverted microscope (magnification, $\mathrm{x} 200$ ). The invasive and migratory abilities of HCC cells were assessed via counting the mean number of migrated or invaded cells in 5 randomly selected fields from each well. Each assay was performed in triplicate. ImageJ $1.48 \mathrm{u}$ software was used to analyze the data.

Statistical analysis. Data are expressed as the mean \pm standard deviation of a minimum of 3 independent experiments. Statistical analysis was performed using SPSS software, version 17.0 (SPSS, Inc., Chicago, IL, USA). The statistical significance of the differences between two groups was assessed using Student's t-test, and when three or more groups were being compared, one-way analysis of variance followed by the least significant difference post hoc test was used. Correlation analysis was conducted using Pearson's test. $\mathrm{P}<0.05$ was considered to indicate a statistically significant difference.

\section{Results}

FoxM1 is overexpressed in HCC cells and is associated with the metastatic potential of cancer cells. FoxM1 mRNA expression was investigated in the human HL-7702 normal hepatocellular cell line and in the SMMC-7721, SK-Hep1 and MHCC-LM3 HCC cell lines using RT-qPCR. The present results demonstrated that the mRNA expression levels of FoxM1 were significantly increased in the HCC cell lines compared with in normal hepatocytes (Fig. 1A). The FoxM1 protein expression in HCC cell lines was observed following western blot analysis (Fig. 1B and C). Notably, the expression levels of FoxM1 in HCC cell lines with different levels of metastasis were investigated. The present findings indicated that FoxM1 was overexpressed in HCC cells, and the expression levels of FoxM1 may have a putative association with the metastatic potential of HCC.

E-cadherin is downregulated in HCC cells. RT-qPCR was performed to investigate the mRNA expression of E-cadherin in HCC cell lines. In comparison with normal hepatocytes, the mRNA expression levels of E-cadherin were significantly decreased in the HCC cell lines (Fig. 2A). In addition, the protein expression levels of E-cadherin were assessed in HCC cell lines 

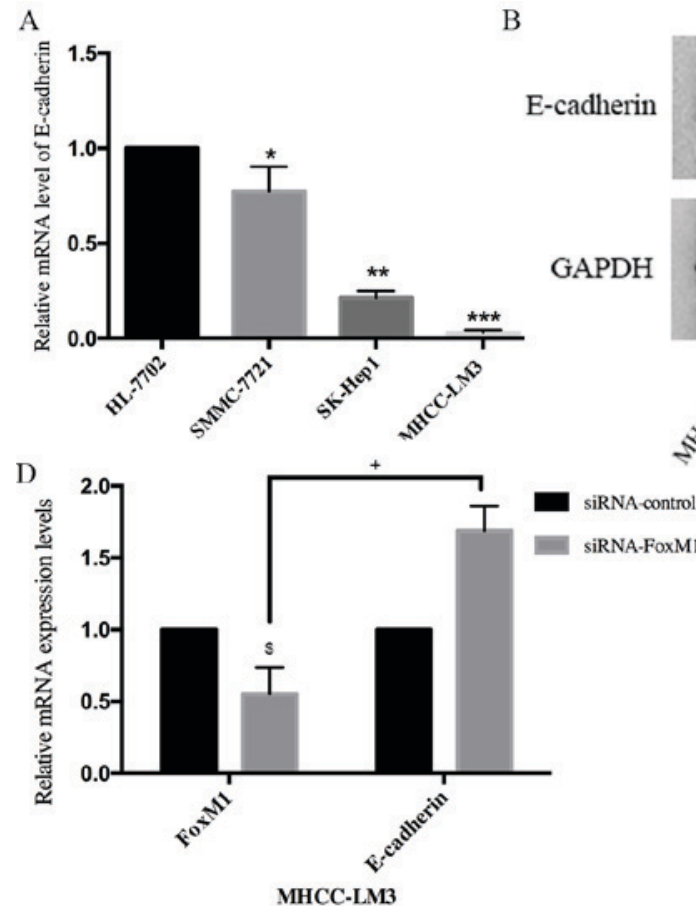

GAPDH

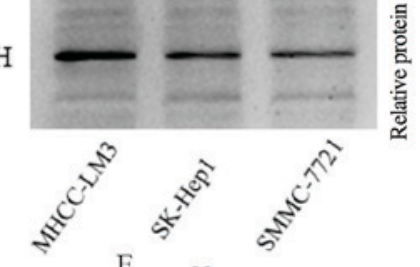

E

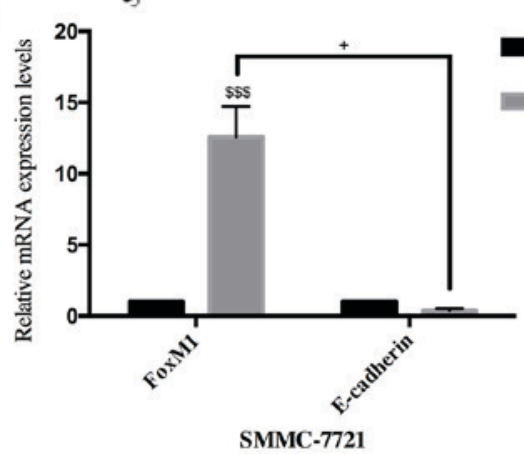

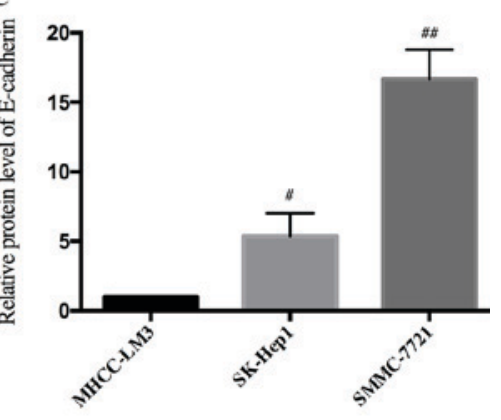

pcDNA3.1-control

pcDNA3.1-FoxM1

Figure 2. The expression of E-cadherin is downregulated in HCC cells. (A) RT-qPCR was used to assess the mRNA expression levels of E-cadherin in the human HL-7702 normal hepatocyte line and in the SMMC-7721, SK-Hep1 and MHCC-LM3 HCC cell lines (SMMC-7721 vs. HL-7702, P=0.031; SK-Hep1 vs. HL-7702, P=0.001; MHCC-LM3 vs. HL-7702 P=0.0002). (B and C) Western blot analysis was used to assess the protein expression levels of E-cadherin in SMMC-7721, SK-Hep1 and MHCC-LM3 HCC cell lines (SK-Hep1 vs. MHCC-LM3, P=0.045; SMMC-7721 vs. MHCC-LM3, P=0.009). (D) RT-qPCR was used to analyze the correlation between FoxM1 and E-cadherin in MHCC-LM3 (P=0.01). (E) RT-qPCR was used to analyze the correlation between FoxM1 and E-cadherin in SMMC-7721 $(\mathrm{P}=0.0165)$. Data are expressed as the mean \pm standard deviation. ${ }^{*} \mathrm{P}<0.05,{ }^{* *} \mathrm{P}<0.01,{ }^{* * *} \mathrm{P}<0.001 \mathrm{vs}$. HL7702; ${ }^{\#} \mathrm{P}<0.05,{ }^{\# \#} \mathrm{P}<0.01$ vs. MHCC-LM3; ${ }^{\$} \mathrm{P}<0.05,{ }^{\$ \$} \mathrm{P}<0.001$ vs. respective control. HCC, hepatocellular carcinoma; RT-qPCR, reverse transcription-quantitative polymerase chain reaction; si, small interfering; FoxM1, forkhead box protein M1; NC, negative control.

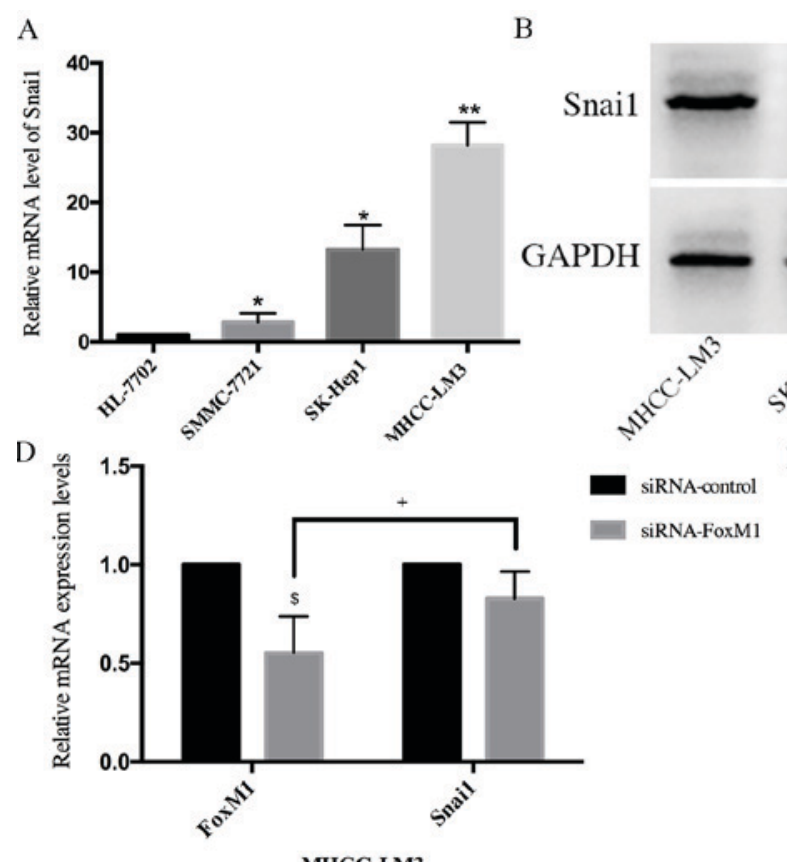

B

C

MHCC-LM3

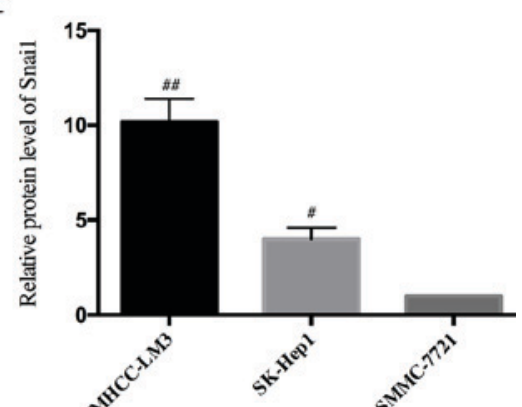

E

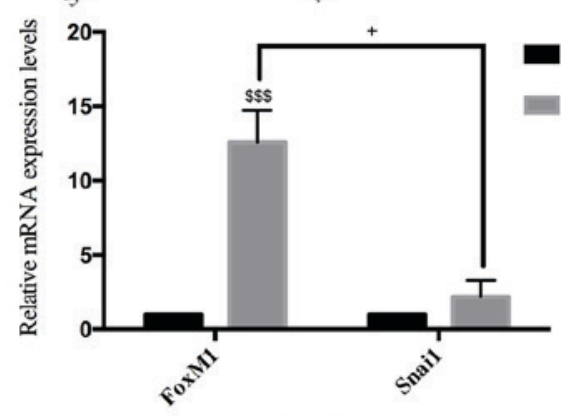

SMMC-7721

Figure 3. Snail expression is upregulated in HCC cells. (A) RT-qPCR was used to assess the mRNA expression levels of Snail in the human HL-7702 normal hepatocyte line and in the SMMC-7721, SK-Hep1 and MHCC-LM3 HCC cell lines (SMMC-7721 vs. HL-7702, P=0.043; SK-Hep1 vs. HL-7702, P=0.027; MHCC-LM3 vs. HL-7702, $\mathrm{P}=0.005$ ). (B and C) Western blot analysis was used to assess the protein expression levels of Snai1 in SMMC-7721, SK-Hep1 and MHCC-LM3 HCC cell lines (MHCC-LM3 vs. SMMC-7721, P=0.009; SK-Hep1 vs. SMCC-7721, P=0.019). (D) RT-qPCR was used to analyze the correlation between FoxM1 and Snai1 in MHCC-LM3 (FoxM1 vs. Snai1, P=0.01). (E) Pearson correlation analysis demonstrated that the overexpression of FoxM1 increased mRNA levels of Snail in SMMC-7721 cells, as further demonstrated by RT-qPCR analysis $(\mathrm{P}=0.026)$. Data are expressed as the mean \pm standard deviation. ${ }^{*} \mathrm{P}<0.05,{ }^{* *} \mathrm{P}<0.01,{ }^{* * * *} \mathrm{P}<0.001$ vs. HL-7702; ${ }^{*} \mathrm{P}<0.05,{ }^{* \#} \mathrm{P}<0.01$ vs. SMCC-7721; ${ }^{\$} \mathrm{P}<0.05,{ }^{\$ \$ \$} \mathrm{P}<0.001$ vs. respective control. Snail, snail family transcriptional repressor 1; HCC, hepatocellular carcinoma; RT-qPCR, reverse transcription-quantitative polymerase chain reaction; si, small interfering; FoxM1, forkhead box protein $\mathrm{M} 1$; NC, negative control. 


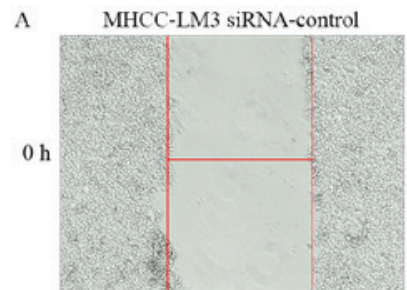

MHCC-LM3 siRNA-FoxM1

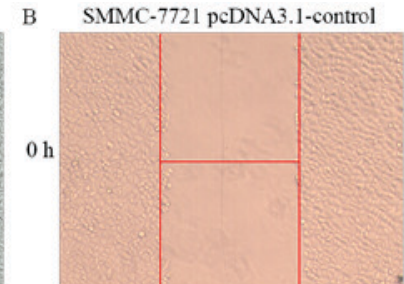

SMMC-7721 pcDNA3.1-FoxM1
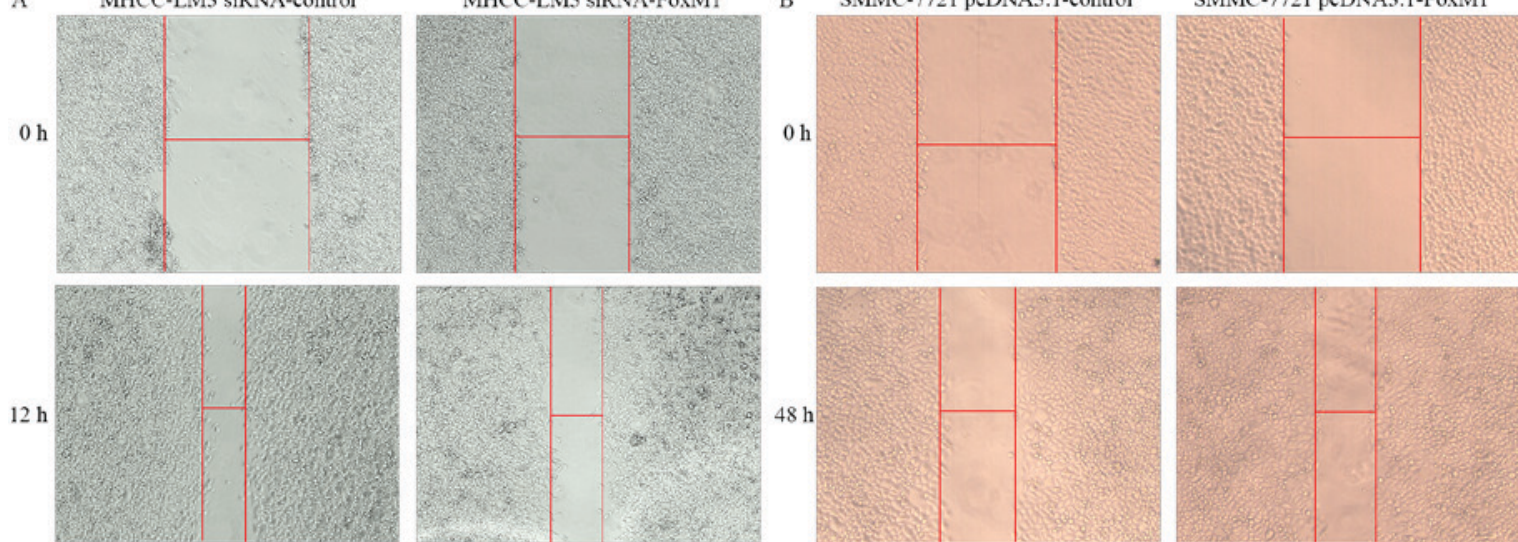

C
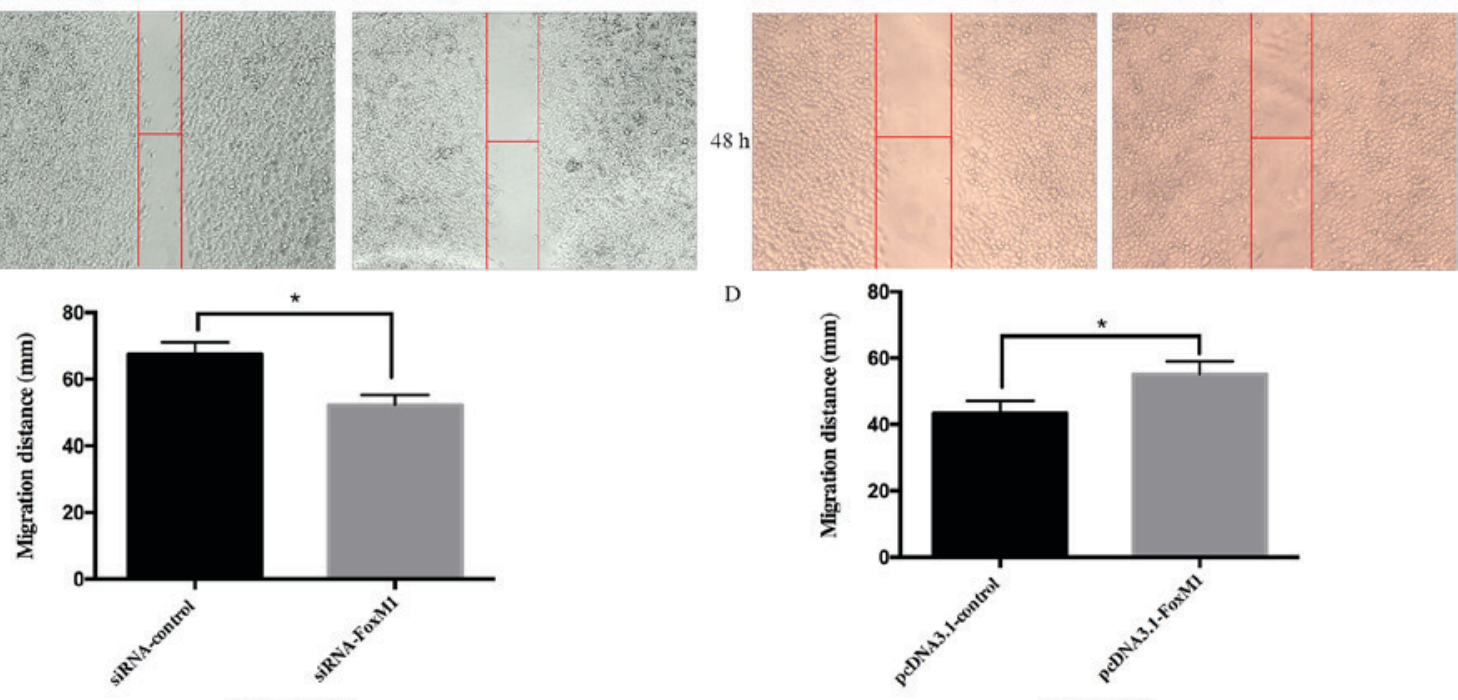

D
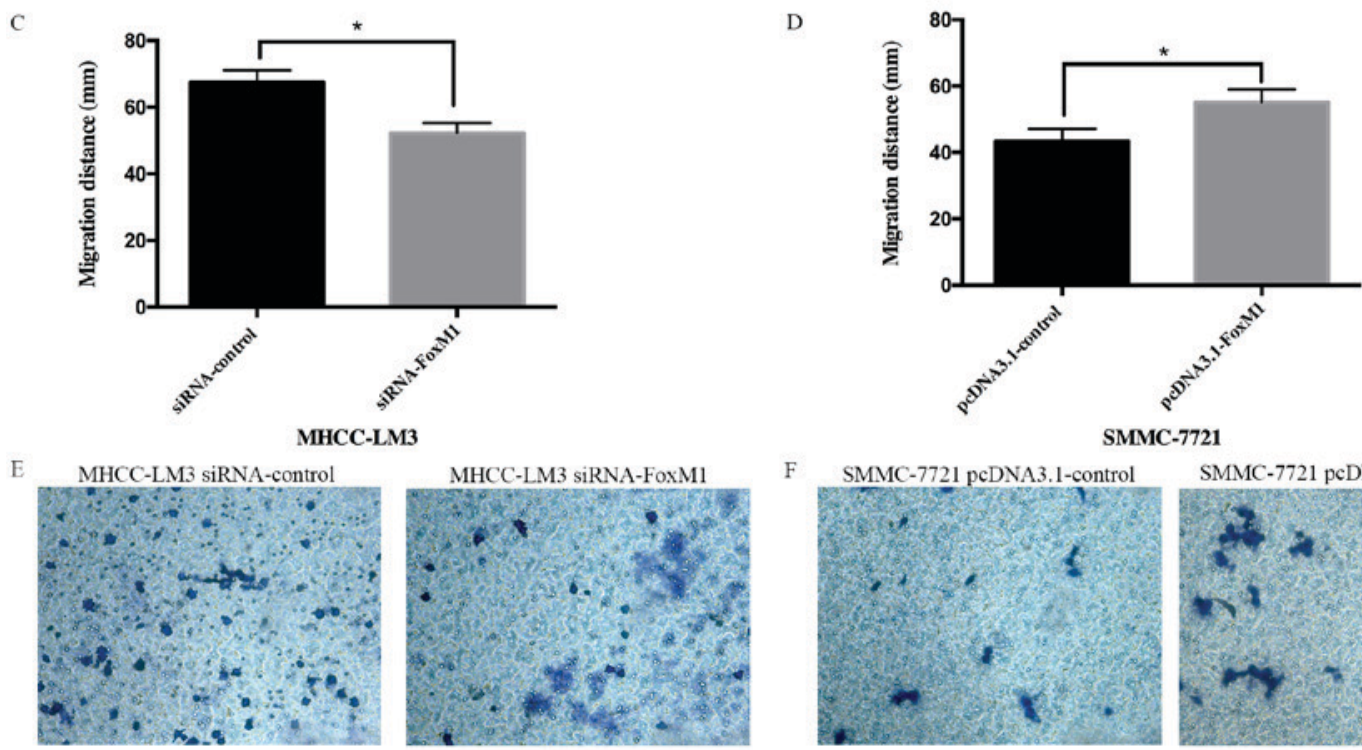

MHCC-LM3 SiRNA-FoxM1
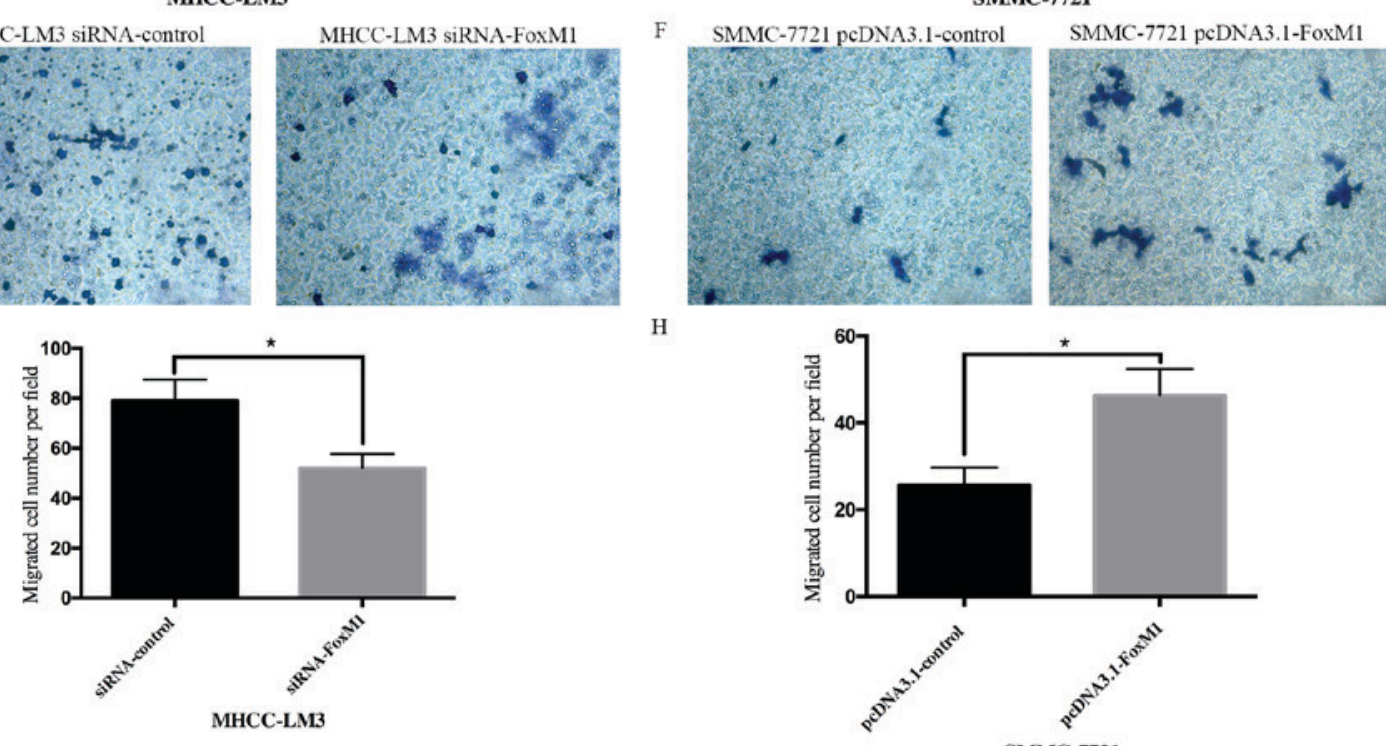

SMMC-7721

Figure 4. FoxM1 overexpression promotes the migration of HCC cells. A wound-healing assay was performed to assess the migratory capabilities of HCC cells. (A) MHCC-LM3 cells were transfected with siRNA-FoxM1 or siRNA-NC; (B) SMMC-7721 cells were transfected with FoxM1 expression vector or empty vector; and this was quantified (C) $\mathrm{P}=0.046$ and (D) $\mathrm{P}=0.047$. A Transwell migration assay was also performed to assess the migratory capabilities of HCC cells. (E) MHCC-LM3 cells were transfected with siRNA-FoxM1 or siRNA-NC; (F) SMMC-7721 cells were transfected with FoxM1 expression vector or empty vector; and this was quantified $(\mathrm{G}) \mathrm{P}=0.034$ and $(\mathrm{H}) \mathrm{P}=0.021$. Data are expressed as the mean \pm standard deviation. ${ }^{*} \mathrm{P}<0.05$. Magnification, $\mathrm{x} 200$. FoxM1, forkhead box protein M1; HCC, hepatocellular carcinoma; si, small interfering; NC, negative control.

with various metastatic potentials using western blot analysis. Consistent with RT-qPCR results, E-cadherin protein exhibited different levels of expression in HCC cell lines with different metastatic potentials (Fig. 2B and C). Furthermore, E-cadherin protein expression levels were significantly lower in the highly metastatic MHCC-LM3 cells compared with in SMMC-7721 cells which have a lower metastatic potential (Fig. 2C).

FoxM1 overexpression downregulates E-cadherin in HCC cells. A previous study reported that overexpression of FoxM1 promoted EMT of cancer cells (17). To investigate the roles of FoxM1 on the expression of E-cadherin in HCC, MHCC-LM3 cells were transfected with siRNA-FoxM1 to silence FoxM1 expression. RT-qPCR was used to determine the success of the transfection (siRNA control vs. siRNA-FoxM1; $\mathrm{P}=0.01382$ ). In addition, the results of the RT-qPCR analysis identified that following knockdown of FoxM1, E-cadherin mRNA and protein expression was significantly upregulated compared with cells transfected with siRNA-NC (Fig. 2D). In order to further investigate the effects of FoxM1 overexpression on 

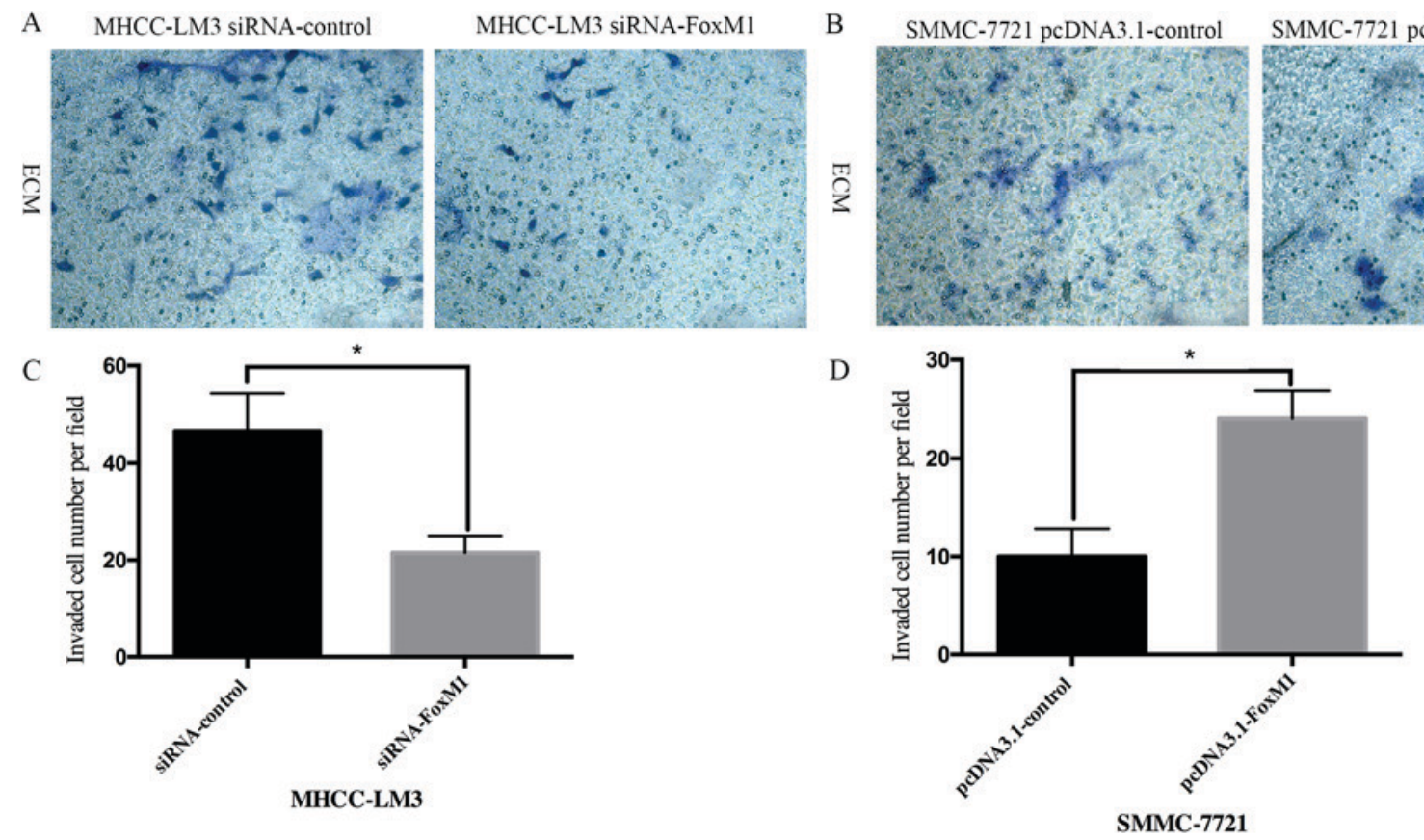

Figure 5. FoxM1 overexpression promotes the invasion of HCC cells. A Transwell invasion assay was used to assess the invasive capabilities of (A) MHCC-LM3 cells transfected with siRNA-FoxM1 or siRNA-NC and (B) of SMMC-7721 cells transfected with FoxM1 expression vector or empty vector. These results were then quantified for $(C)$ MHCC-LM3 cells $(\mathrm{P}=0.048)$ and $(\mathrm{D})$ SMMC-7721 cells $(\mathrm{P}=0.038)$. Data are expressed as the mean \pm standard deviation. ${ }^{*} \mathrm{P}<0.05$. Magnification, x200. FoxM1, forkhead box protein M1; HCC, hepatocellular carcinoma; si, small interfering; NC, negative control.

the expression of E-cadherin, the FoxM1 expression vector pcDNA3.1-FoxM1 was transfected into SMMC-7721 cells, which typically express lower levels of FoxM1 compared with MHCC-LM3 cells (Fig. 1). RT-qPCR was used to determine the success of the transfection (pcDNA3.1-control vs. pcDNA3.1-FoxM1; $\mathrm{P}=0.00073$ ). The mRNA and protein expression levels of E-cadherin were significantly decreased in pcDNA3.1-FoxM1-transfected SMMC-7721 cells compared with NC cells (Fig. 2E). The present findings suggested that FoxM1 may downregulate the expression of E-cadherin in HCC cells, and it may be involved in the process of EMT.

Snail is upregulated in HCC cells and its expression is regulated by FoxM1. A previous study suggested that Snai1 may be involved in the molecular mechanisms underlying the roles of FoxM1 in EMT (17). Therefore, the present study investigated the expression of Snail in HCC cell lines using RT-qPCR and western blot analysis (Fig. 3A-C). The present results demonstrated that Snail mRNA expression levels were significantly increased in HCC cells compared with normal hepatocytes, and the mRNA and protein expression of Snail in HCC cells with different metastatic potentials exhibited consistent expression characteristics (Fig. 3 A-C). Notably, Snail expression was observed to be positively correlated with FoxM1 expression in HCC cells (Fig. 3D and E). These observations suggested that Snail may be implicated in the pathways involved in FoxM1-mediated EMT in HCC cells.

FoxM1 promotes the migration and invasion of HCC cells. To investigate the effects of FoxM1 on the migratory capabilities of HCC cells, cells were transfected with siRNA-FoxM1 or pcDNA3.1-FoxM1 and wound-healing and Transwell migration assays were performed. Knockdown of FoxM1 expression resulted in the slower healing of scratch wounds inflicted on MHCC-LM3 cells (Fig. 4A and C), whereas its overexpression potentiated the healing of scratch wounds in SMMC-7721 cells (Fig. 4B and D), compared with NC cells. Similar results were observed following a Transwell migration assay, as the migratory capabilities of HCC cells were impaired following FoxM1 silencing, whereas they were enhanced following its overexpression (Fig. 4E-H).

To further explore the roles of FoxM1 in HCC cell invasion, a Transwell invasion assay was performed following FoxM1 knockdown or overexpression. The present results demonstrated that the invasive capabilities of siRNA-FoxM1-transfected MHCC-LM3 cells were significantly impaired compared with siRNA-NC-transfected cells (Fig. 5A and C). Conversely, following FoxM1 overexpression, the number of invaded SMMC-7721 cells was significantly increased compared with NC cells (Fig. 5B and D).

These observations suggested that the overexpression of FoxM1 may promote the migratory and invasive capabilities of HCC cells. Conversely, knockdown of FoxM1 expression may suppress the migration and invasion of HCC cells.

\section{Discussion}

Due to the characteristics of metastasis and invasion of malignant tumors, it was estimated that $90 \%$ of patients with cancer succumbed as a result of tumor metastasis in 2015 (23). $\mathrm{HCC}$ is a fast-growing type of tumor that is characterized by a rich blood supply and high invasive and metastatic capabilities $(4,24)$. A total of $\sim 60-80 \%$ of patients with HCC are diagnosed at an advanced stage, thus losing the opportunity for surgical treatment (3). 
In the present study, the oncogene FoxM1 was identified to be overexpressed in HCC cells compared with normal hepatocytes. Notably, the expression of FoxM1 was positively correlated with the metastatic potential of HCC cells. In addition, FoxM1 overexpression was demonstrated to promote the invasion and metastasis of HCC cells, whereas its knockdown produced the opposite results.

The roles of E-cadherin in the invasion and metastasis of tumors have gained attention $(17,25,26)$, and the results of the present study suggested that FoxM1 silencing may inhibit the metastasis of HCC cells via interfering with E-cadherin signaling. Notably, Snail expression was indicated to be upregulated following FoxM1 overexpression and E-cadherin downregulation. These results suggested that Snail may be involved in FoxM1-mediated E-cadherin regulation. Wei et al (27) reported that FoxM1 could directly bind to the promoter region of the Snail gene and upregulate its expression in human lung adenocarcinoma cells. In addition, Snail has been demonstrated to bind to target genes that contain the enhanced box (E-box; CAGGTG) DNA response element $(28,29)$. The E-box of the E-cadherin promoter has been demonstrated to possess Snail binding sites: Snail can bind to the E-cadherin promoter and recruit histone deacetylase (HDAC) 1, HDAC2 and Sin3A to acetylated histones $\mathrm{H} 3$ and $\mathrm{H} 4$, thus silencing the expression of E-cadherin (9). The results of the present study suggested that FoxM1 overexpression may enhance the transcription of Snai1, thus suppressing the expression of E-cadherin and promoting HCC invasion and metastasis. However, FoxM1 has also been reported to directly activate the E-cadherin promoter (30); therefore, further studies are required to fully elucidate the molecular mechanisms underlying the FoxM1-mediated regulation of E-cadherin, and their involvement in $\mathrm{HCC}$ metastasis.

FoxM1 is an oncogene and has been identified to be involved in various pathways implicated in cancer metastasis (31-33). FoxM1 has been reported to regulate the expression of matrix metalloproteinase (MMP)-2 and MMP-9, and thus potentiate extracellular matrix degradation and enhance the motility and invasion of cancer cells (34). In addition, FoxM1 has been demonstrated to promote tumor angiogenesis, migration and invasion, via regulating the expression of the vascular endothelial growth factor gene (35). Furthermore, miRNAs have been reported to combine with the 3'-untranslated region of the FoxM1 mRNA to downregulate its expression and thus inhibit tumor metastasis (36). Therefore, FoxM1 appears to serve an important role in several signaling pathways involved in cancer metastasis.

The Wnt/ $\beta$-catenin signaling pathway has been implicated in EMT. FoxM1 has been identified as a downstream factor in the Wnt signaling pathway, as it can combine with $\beta$-catenin to enhance its transcriptional activity and nuclear localization (37). In the nucleus, $\beta$-catenin forms a $\beta$-catenin-/T cell factor/lymphoid enhancer-binding factor transcription complex, leading to the activation of transcription of target genes that are implicated in EMT (38). In addition, the activation of Wnt signaling has been demonstrated to enhance the expression of Snail (39). Therefore, the results of the present study suggested that FoxM1 may downregulate the expression of E-cadherin through the induction of Snail, possibly via the Wnt/ $\beta$-catenin signaling pathway, and thus promote EMT in HCC.
In conclusion, the present results suggested that FoxM1 may serve a critical role in the regulation of EMT in cancer cells and HCC metastasis. Overexpression of FoxM1 has previously been associated with the poor prognosis of HCC (40), thus suggesting that FoxM1 may have potential as a biomarker for the early diagnosis of HCC and the evaluation of its prognosis, and may provide a novel therapeutic target for the treatment of patients with HCC.

\section{Acknowledgements}

The present study was supported by the National Natural Science Foundation of China (grant nos. 81372632 and 81402579) and the Special Funds of Postdoctoral Innovation Projects of Shandong Province of China (grant no. 201303063).

\section{References}

1. Jemal A, Bray F, Center MM, Ferlay J, Ward E and Forman D: Global cancer statistics. CA Cancer J Clin 61: 69-90, 2011.

2. Lee SC, Tan HT and Chung MC: Prognostic biomarkers for prediction of recurrence of hepatocellular carcinoma: Current status and future prospects. World J Gastroenterol 20: 3112-3124, 2014.

3. Yang JD, Harmsen WS, Slettedahl SW, Chaiteerakij R, Enders FT, Therneau TM, Orsini L, Kim WR and Roberts LR: Factors that affect risk for hepatocellular carcinoma and effects of surveillance. Clin Gastroenterol Hepatol 9: 617-623.e1, 2011.

4. Bruix J, Gores GJ and Mazzaferro V: Hepatocellular carcinoma: Clinical frontiers and perspectives. Gut 63: 844-855, 2014.

5. Greenburg G and Hay ED: Epithelia suspended in collagen gels can lose polarity and express characteristics of migrating mesenchymal cells. J Cell Biol 95: 333-339, 1982.

6. Christiansen JJ and Rajasekaran AK: Reassessing epithelial to mesenchymal transition as a prerequisite for carcinoma invasion and metastasis. Cancer Res 66: 8319-8326, 2006.

7. Inayoshi J, Ichida T, Sugitani S, Tsuboi Y, Genda T, Honma N and Asakura H: Gross appearance of hepatocellular carcinoma reflects $E$-cadherin expression and risk of early recurrence after surgical treatment. J Gastroenterol Hepatol 18: 673-677, 2003.

8. Miao L, Xiong X, Lin Y, Cheng Y, Lu J, Zhang J and Cheng N: Down-regulation of FoxM1 leads to the inhibition of the epithelial-mesenchymal transition in gastric cancer cells. Cancer Genet 207: 75-82, 2014

9. Yang C, Chen H, Tan G, Gao W, Cheng L, Jiang X, Yu L and Tan Y: FOXM1 promotes the epithelial to mesenchymal transition by stimulating the transcription of Slug in human breast cancer. Cancer Lett 340: 104-112, 2013.

10. Deep G, Jain AK, Ramteke A, Ting H, Vijendra KC, Gangar SC, Agarwal C and Agarwal R: SNAI1 is critical for the aggressiveness of prostate cancer cells with low E-cadherin. Mol Cancer 13: 37, 2014.

11. Franco-Chuaire ML, Magda Carolina SC and Chuaire-Noack L: Epithelial-mesenchymal transition (EMT): Principles and clinical impact in cancer therapy. Invest Clin 54: 186-205, 2013.

12. Korver W, Roose J, Heinen K, Weghuis DO, de Bruijn D, van Kessel AG and Clevers H: The human TRIDENT/HFH11/FKHL16 gene: Structure, localization, and promoter characterization. Genomics 46: 435-442, 1997.

13. Ye H, Kelly TF, Samadani U, Lim L, Rubio S, Overdier DG, Roebuck KA and Costa RH: Hepatocyte nuclear factor 3/fork head homolog 11 is expressed in proliferating epithelial and mesenchymal cells of embryonic and adult tissues. Mol Cell Biol 17: 1626-1641, 1997.

14. Gong A and Huang S: FoxM1 and Wnt/ $\beta$-catenin signaling in glioma stem cells. Cancer Res 72: 5658-5662, 2012.

15. Laoukili J, Kooistra MR, Brás A, Kauw J, Kerkhoven RM, Morrison A, Clevers H and Medema RH: FoxM1 is required for execution of the mitotic programme and chromosome stability. Nat Cell Biol 7: 126-136, 2005.

16. Korver W, Roose J and Clevers H: The winged-helix transcription factor Trident is expressed in cycling cells. Nucleic Acids Res 25: 1715-1719, 1997. 
17. Meng FD, Wei JC, Qu K, Wang ZX, Wu QF, Tai MH, Liu HC, Zhang RY and Liu C: FoxM1 overexpression promotes epithelial-mesenchymal transition and metastasis of hepatocellular carcinoma. World J Gastroenterol 21: 196-213, 2015.

18. Jiang W, Zhou F, Li N, Li Q and Wang L: FOXM1-LDHA signaling promoted gastric cancer glycolytic phenotype and progression. Int J Clin Exp Pathol 8: 6756-6763, 2015.

19. Luo X, Yao J, Nie P, Yang Z, Feng H, Chen P, Shi X and Zou Z: FOXM1 promotes invasion and migration of colorectal cancer cells partially dependent on HSPA5 transactivation. Oncotarget 7: 26480-26495, 2016

20. Lam EW, Brosens JJ, Gomes AR and Koo CY: Forkhead box proteins: Tuning forks for transcriptional harmony. Nat Rev Cancer 13: 482-495, 2013.

21. Park HJ, Gusarova G, Wang Z, Carr JR, Li J, Kim KH, Qiu J, Park YD, Williamson PR, Hay N, et al: Deregulation of FoxM1b leads to tumour metastasis. EMBO Mol Med 3: 21-34, 2011.

22. Livak KJ and Schmittgen TD: Analysis of relative gene expression data using real-time quantitative PCR and the 2(-Delta Delta C(T)) method. Methods 25: 402-408, 2001.

23. Guan X: Cancer metastases: Challenges and opportunities. Acta Pharm Sin B 5: 402-418, 2015.

24. Nordenstedt H, White DL and El-Serag HB: The changing pattern of epidemiology in hepatocellular carcinoma. Dig Liver Dis 42 (Suppl 3): S206-S214, 2010.

25. Yang $J$ and Weinberg RA: Epithelial-mesenchymal transition: At the crossroads of development and tumor metastasis. Dev Cell 14: 818-829, 2008.

26. Sánchez-Tilló E, Lázaro A, Torrent R, Cuatrecasas M, Vaquero EC, Castells A, Engel P and Postigo A: ZEB1 represses E-cadherin and induces an EMT by recruiting the SWI/SNF chromatin-remodeling protein BRG1. Oncogene 29: 3490-3500, 2010.

27. Wei P, Zhang N, Wang Y, Li D4, Wang L, Sun X, Shen C, Yang Y, Zhou $\mathrm{X}$ and Du X: FOXM1 promotes lung adenocarcinoma invasion and metastasis by upregulating SNAIL. Int J Biol Sci 11: 186-198, 2015.

28. Balli D, Ustiyan V, Zhang Y, Wang IC, Masino AJ, Ren X, Whitsett JA, Kalinichenko VV and Kalin TV: Foxm1 transcription factor is required for lung fibrosis and epithelial-to-mesenchymal transition. EMBO J 32: 231-244, 2013.
29. Tao G, Levay AK, Gridley T and Lincoln J: Mmp15 is a direct target of Snail during endothelial to mesenchymal transformation and endocardial cushion development. Dev Biol 359: 209-221, 2011.

30. Wierstra I: The transcription factor FOXM1c binds to and transactivates the promoter of the tumor suppressor gene E-cadherin. Cell Cycle 10: 760-766, 2011.

31. Wang Z, Ahmad A, Li Y, Banerjee S, Kong D and Sarkar FH: Forkhead box M1 transcription factor: A novel target for cancer therapy. Cancer Treat Rev 36: 151-156, 2010.

32. Halasi M and Gartel AL: FOX(M1) news-it is cancer. Mol Cancer Ther 12: 245-254, 2013.

33. Ke Y,Zhao W,Xiong J and Cao R: miR-149 inhibits non-small-cell lung cancer cells EMT by targeting FOXM1. Biochem Res Int 2013: 506731, 2013.

34. Wei JC, Meng FD, Qu K, Wang ZX, Wu QF, Zhang LQ, Pang Q and Liu C: Sorafenib inhibits proliferation and invasion of human hepatocellular carcinoma cells via up-regulation of p53 and suppressing FoxM1. Acta Pharmacol Sin 36: 241-251, 2015.

35. Karadedou CT, Gomes AR, Chen J, Petkovic M, Ho KK, Zwolinska AK, Feltes A, Wong SY, Chan KY, Cheung YN, et al: FOXO3a represses VEGF expression through FOXM1-dependent and -independent mechanisms in breast cancer. Oncogene 31: 1845-1858, 2012.

36. Sun Y, Yu X and Bai Q: miR-204 inhibits invasion and epithelial-mesenchymal transition by targeting FOXM1 in esophageal cancer. Int J Clin Exp Pathol 8: 12775-12783, 2015.

37. Kahn M: Can we safely target the WNT pathway? Nat Rev Drug Discov 13: 513-532, 2014.

38. Pongracz JE and Stockley RA: Wnt signalling in lung development and diseases. Respir Res 7: 15, 2006.

39. Wu ZQ, Li XY, Hu CY, Ford M, Kleer CG and Weiss SJ: Canonical Wnt signaling regulates Slug activity and links epithelial-mesenchymal transition with epigenetic breast cancer 1, early onset (BRCA1) repression. Proc Natl Acad Sci USA 109: 16654-16659, 2012.

40. Wen N, Wang Y, Wen L, Zhao SH, Ai ZH, Wang Y, Wu B, Lu HX, Yang H, Liu WC and Li Y: Overexpression of FOXM1 predicts poor prognosis and promotes cancer cell proliferation, migration and invasion in epithelial ovarian cancer. J Transl Med 12: 134, 2014. 